\title{
Gregory Poole Talks Progress in Metallurgical Processing
}
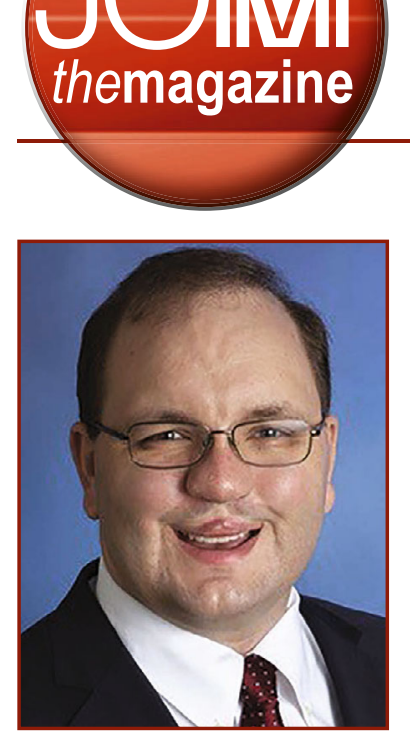

Gregory M. Poole

\section{young professional technical notes}

This occasional

feature highlights the

scientific interests

and professional

accomplishments of a

young TMS member

who has contributed to

the technical content

of the current issue

of JOM as an author,

advisor, or guest editor.

The development of

this feature is a special

project of the TMS

Young Professionals

Committee. For

additional information

contact Kaitlin Calva,

JOM Magazine

Managing Editor, at

kcalva@tms.org.

\section{Kaitlin Calva}

"Never be afraid to say 'I don't know," said Gregory M. Poole, co-author of "Comparison of Coil Configuration and Position on Flow Characteristics of A319 Aluminum in Electromagnetically Stirred Solidification Systems," published in the January 2019 CFD Modeling and Simulation in Materials Processing JOM topic. "Today, there is an unreasonable apprehension to utter those words, either out of pride or the fear of looking incompetent in our fast-paced world. But those three words have done more to spur progress and the creation of our modern way of life than any others."

An assistant professor of mechanical engineering at the University of South Alabama, Poole has two other pieces of advice for young scientists and engineers. First, "Be sure to take a few hours each week for self-care... rest time is essential to reach each successive peak." The second is something Poole tells his own students. "Three strikes and you're not out. Just because you make mistakes does not mean you are not well-prepared for the future. What it takes, above all, is contentiousness and maintaining a sense of wonder about the world around you."

He has managed to keep his own sense of wonder about the world of metallurgy since an early age with the help of David Nikles, having found his calling to teach others and to perform science and engineering research during a high school internship with Nikles at the University of Alabama. As he continued on to pursue his B.S., M.S., and Ph.D., all in metallurgical engineering, Poole noted that it was Nagy El-Kaddah, his graduate advisor and friend, and Laurentiu Nastac, his co-author on the January 2019 JOM paper, who "deepened my love for metallurgy and molten metal processing, and emphasized that my classmates and I always master the fundamentals in answering scientific questions." During his postdoctoral work at Purdue University, Matthew J.M. Krane helped Poole become a better educator. "I learned how to demand excellence both of myself and those I mentor," he said. "To not ask the best of individuals is to hinder them from achieving their full potential."

Poole's current research is an extension of his graduate work in the use of electromagnetic fields in solidification processing. "This article is a culmination of work in magnetohydrodynamics and the role that operating parameters have on heat and momentum transfer within solidifying castings," Poole said. "I hope it will provide valuable insight on which parameters take precedence in electromagnetic stirring of semisolid melts."

Recently, Poole has expanded his work with the help of his colleagues in the Chemistry Department to include the "development of new stereolithography resins with tunable mechanical and thermal properties." Poole counts new ventures like these as milestones along the road of his academic career. "Being able to realize the usefulness of knowledge gained through my professional life in mechanical behavior, metallurgy, and materials science has been such a blessing." Looking to the future of the field, Poole notes that "One of our greatest challenges will be making metalcasting and downstream processes environmentally sustainable for the coming generations as we look for ways to enact material and energy savings."

A TMS member since his undergraduate days, Material Advantage helped expose Poole to different materials classes while keeping him engaged in the field. And now, as a professional member, Poole still finds a "true community" in the Society: "Attending TMS conferences allows you to connect with individuals who are likewise fascinated with metallurgy but whose specialty differs from your own. There is no truly isolated area in metallurgy/ materials science, and as scientists and engineers we all have something to learn from one another." 